\title{
Development of cardiac remodeling in patients with acute myocardial infarction studied by cardiac MRI (CMR)
}

\author{
Martin R Sinn ${ }^{1 *}$, Enver Tahir ${ }^{1}$, Ulf K Radunski ${ }^{2}$, Dennis Säring ${ }^{3}$, Maxim Avanesov ${ }^{1}$, Kai Muellerleile², Gerhard Adam', \\ Gunnar Lund ${ }^{1}$
}

From 18th Annual SCMR Scientific Sessions

Nice, France. 4-7 February 2015

\section{Background}

Left ventricular (LV) remodeling after acute myocardial infarction (AMI) is defined as a progressive increase of end-diastolic volume (EDV) $\geq 20 \%$ compared to baseline (BL). However, the exact occurrence of LV remodeling and the further development of EDV after AMI is unclear.

\section{Methods}

LV myocardial mass, volumes, and function were assessed in 25 patients after reperfused first AMI using cine and delayed enhancement imaging. Patients under- went CMR within $7 \pm 4.9$ days (baseline, BL) after AMI. Follow-up scans were performed at $1.25 \pm 0.27$ months (FU1), $3.3 \pm 0.56$ months (FU2) and $6.27 \pm 0.65$ months (FU3).

\section{Results}

Two types of LV remodeling were observed. Three of 25 patients (12\%) (age: $55 \pm 7$ years) showed normal EDV at baseline with $166 \pm 12 \mathrm{ml}$, but significantly increased EDV with $219 \pm 32 \mathrm{ml}$ at $\mathrm{FU} 1(P<0.01 \mathrm{vs} \mathrm{BL})$. At FU2 and FU3 no further changes in EDV were detected in these patients (Table 1$)$. Another three patients (12\%,

Table 1 Data are presented as mean \pm SD of patients.

\begin{tabular}{|c|c|c|c|c|c|}
\hline & & $\mathrm{BL}$ & FU1 & FU2 & FU3 \\
\hline \multirow[t]{3}{*}{ EDV [ml] } & No remodeling $(n=19)$ & $143 \pm 27$ & $156 \pm 31$ & $152 \pm 28$ & $150 \pm 32$ \\
\hline & Delayed remodeling $(n=3)$ & $166 \pm 12^{\dagger}$ & $219 \pm 32^{* \#}$ & $209 \pm 58^{*}$ & $211 \pm 32^{*}$ \\
\hline & Early remodeling $(n=3)$ & $251 \pm 44^{*}$ & $246 \pm 20^{*}$ & $240 \pm 27^{*}$ & $247 \pm 34^{*}$ \\
\hline \multirow[t]{3}{*}{ Infarct size [\% of LV] } & No remodeling $(n=19)$ & $12 \pm 8$ & $11 \pm 8$ & $10 \pm 8$ & $9 \pm 7$ \\
\hline & Delayed remodeling $(n=3)$ & $25 \pm 7^{*}$ & $26 \pm 8^{*}$ & $25 \pm 6^{*}$ & $23 \pm 8^{*}$ \\
\hline & Early remodeling $(n=3)$ & $22 \pm 8^{*}$ & $19 \pm 9^{*}$ & $16 \pm 12^{*}$ & $20 \pm 7^{*}$ \\
\hline \multirow[t]{3}{*}{ EF [\%] } & No remodeling $(n=19)$ & $56 \pm 9$ & $58 \pm 8$ & $58 \pm 7$ & $61 \pm 8$ \\
\hline & Delayed remodeling $(n=3)$ & $47 \pm 11$ & $44 \pm 16$ & $46 \pm 18$ & $45 \pm 11$ \\
\hline & Early remodeling $(n=3)$ & $33 \pm 5^{*}$ & $37 \pm 2^{*}$ & $39 \pm 7^{*}$ & $46 \pm 7^{*}$ \\
\hline
\end{tabular}

* $\mathrm{P}<0.01$ vs no remodeling

$\# \mathrm{P}<0.05$ vs $\mathrm{BL}$

$\dagger P=n s$ vs no remodeling 
age: $45 \pm 8$ years) showed early remodeling with significantly increased EDV of $>200 \mathrm{ml}$ at BL and no further change of EDV during follow-up (Table 1). Infarct size was significantly higher in the group of patients with remodeling compared to patients without remodeling (Table 1). At BL, patients with early remodeling had a significantly lower ejection fraction (EF) with $33 \pm 5 \%$ compared to patients with no remodeling $(56 \pm 9 \%$, $P<0.01)$. At FU3, patients with early remodeling show recovery in function, whereas patients with delayed remodeling showed no change in EF during follow-up (Table 1).

\section{Conclusions}

Remodeling occurred in 6 of 25 patients (24\%) after AMI. Three patients (12\%) showed early remodeling with increased EDV and low EF already at BL, which improved at 6 months follow- up. In another three patients (12\%) delayed remodeling occurred at FU1 with stable EDV and EF at later follow-up. Remodeling occurs in patients with large infarction either early with initially increased EDV and or delayed with initially normal EDV. Early remodeling is characterized by initially severely reduced EF with recovery in EF at 6 months follow-up.

\section{Funding}

This study is partially funded by the Deutsche Forschungsgemeinschaft.

\section{Authors' details}

${ }^{1}$ Department of Diagnostic and Interventional Radiology, University Medical Center Hamburg-Eppendorf, Hamburg, Germany, Hamburg, Germany.

¿2Departments of Cardiology, University Medical Center Hamburg-Eppendorf, Hamburg, Germany. ${ }^{3}$ Department of of Computational Neuroscience, University Medical Center Hamburg-Eppendorf, Hamburg, Germany, Hamburg, Germany.

Published: 3 February 2015

doi:10.1186/1532-429X-17-S1-P130

Cite this article as: Sinn et al: Development of cardiac remodeling in patients with acute myocardial infarction studied by cardiac MRI (CMR). Journal of Cardiovascular Magnetic Resonance 2015 17(Suppl 1):P130.
Submit your next manuscript to BioMed Central and take full advantage of:

- Convenient online submission

- Thorough peer review

- No space constraints or color figure charges

- Immediate publication on acceptance

- Inclusion in PubMed, CAS, Scopus and Google Scholar

- Research which is freely available for redistribution

Submit your manuscript at www.biomedcentral.com/submit 